\title{
AUTOCONSCIÊNCIA E AMBIGUIDADE PERCEPTUAL CINESTÉSICA: EXPERIMENTO FENOMENOLÓGICO ${ }^{1}$
}

\author{
Thiago Gomes de Castro* \\ William Barbosa Gomes
}

\begin{abstract}
RESUMO. Relações entre cinestesia e autoconsciência foram examinadas em experimento fenomenológico com 19 estudantes universitários, os quais responderam a três instrumentos: 1) Escala de Autoconsciência; 2) The Alien-hand Experiment (indução de distorção perceptiva em tarefa motora, repetida quatro vezes); e 3) Entrevista Fenomenológica sobre percepções do experimento. A análise identificou dois padrões de resposta: 1) reconhecimento da distorção e atribuição ao experimento e 2) reconhecimento ambivalente da distorção e atribuição a si mesmo. O segundo padrão de resposta associou-se a altos índices de autoconsciência. A reversão entre experiência consciente e consciência da experiência desvelou-se gradativamente nas repetições da tarefa: 1) descrição do estranhamento, 2) variações imaginárias das causas da distorção (arguições), 3) tomada de posição pela atribuição da distorção ao experimento ou a dificuldade pessoal de realizar a tarefa. A diferenciação de modalidades de autoconsciência permitiu a análise da arguição sobre as interferências experimentais, apontando de modo original o movimento da pré-reflexão à autorreflexão.
\end{abstract}

Palavras-chave: Fenomenologia experimental, autoconsciência, percepção.

\section{SELF-CONSCIOUSNESS AND KINESTHETIC PERCEPTUAL AMBIGUITY: PHENOMENOLOGICAL EXPERIMENT}

\begin{abstract}
Relations between kinesthesia and selfconsciousness were examined in a phenomenological experiment with 19 students who responded to three instruments: 1) Self-Consciousness Scale (private, public and social anxiety), 2) The Alien-Hand Experiment (purposely-induced distortion in perceptual motor task, repeated four times) and 3) Phenomenological interview on perceptions of the experiment. The analysis identified two patterns of response: 1) recognition of the distortion and assignment to the experiment, and 2) ambivalent recognition of distortion and attribution to himself. The second response pattern was associated with high levels of selfconsciousness. Reversal between experience conscious and consciousness of experience were revealed gradually in the repetitions of the task: 1) description of estrangement, 2) imaginary variations on the causes of distortion (arguments), 3) decision making between positing distortions on experiment variables or personnel difficulty to perform the task. Differentiation of self-consciousness modalities led to argument analysis on task interferences, pointing to an original handling of pre-reflection to self-reflection.
\end{abstract}

Key words: Experimental phenomenology, self-consciousness, perception.

\section{AUTOCONCIENCIA Y PERCEPCIÓN KINESTÉSICA DE AMBIGUEDAD: EXPERIMENTO FENOMENOLÓGICO}

RESUMEN. Relaciones entre cinestesia y autoconciencia se examinaron en un experimento fenomenológico con 19 estudiantes que respondieron a tres instrumentos: 1) Escala de Autoconciencia (privado, público y ansiedad social), 2) The Alien-Hand Experiment (inducción deliberada a la distorsión perceptual en tarea motora, repetida cuatro veces) y 3) entrevista fenomenológica, sobre la percepción de la experiencia. El análisis identificó dos patrones de respuesta: 1) el reconocimiento de la distorsión y la asignación a lo experimento, y 2) el reconocimiento ambivalente de la distorsión y la atribución a sí mismo. El segundo patrón de respuesta se asoció con altos niveles de autoconciencia. Inversión entre la experiencia consciente y la conciencia de la experiencia se reveló gradualmente en las repeticiones de la tarea: 1) descripción de extrañamiento, 2) las variaciones imaginario sobre las causas de la distorsión (argumentos), 3) la toma de decisiones entre la postulación de distorsión en las variables del experimento o la dificultad personal para realizar la tarea.

Palabras-clave: Fenomenología experimental, autoconciencia, percepción.

Apoio: CNPq.

Doutorando em Psicologia/UFRGS, Laboratório de Fenomenologia Experimental e Cognição.

\# Doutor em Higher Education pela Southern Illinois University Carbondale, Estados Unidos. Professor Adjunto da Universidade Federal do Rio Grande do Sul, Brasil. 
A articulação metodológica entre fenomenologia e experimentação tem servido a investigações recentes sobre a experiência de ambiguidade perceptual em seres humanos (Grush, 2006). Para Gallagher e Sorensen (2006), a chamada fenomenologia experimental contempla duas modalidades de condução de pesquisa. A primeira refere-se ao treino de resposta dos participantes no contexto experimental e no próprio método fenomenológico; e a segunda não envolve o treino dos participantes no método fenomenológico, solicitando apenas relatos de experiência em situações induzidas de tarefa experimental. Esse modelo tem sido utilizado em estudos sobre autorreconhecimento (Farrer \& Frith, 2002) e senso de agência (Daprati et al., 1997; Sorensen, 2005), em condições experimentais controladas que suscitam movimentos corporais voluntários e involuntários. A presente pesquisa se insere nesse segundo patamar de experimentação em fenomenologia. Para tanto replica uma tarefa induzida (Nielsen, 1963), com o objetivo de avaliar a relação entre percepção cinestésica e índices de autoconsciência reflexiva. Como percepção cinestésica entende-se a sensação de movimento do próprio corpo em uma dimensão espaçotemporal (Petit, 2010); e autoconsciência reflexiva é a capacidade humana de se tornar objeto da própria atenção (Silvia, Jones, Kelly \& Zibaie, 2010).

\section{PERCEPÇÃO CINESTÉSICA E O "EXPERIMENTO DA MÃO ALIENÍGENA"}

Em 1963 o pesquisador dinamarquês Torsten Nielsen publicou um artigo no qual introduziu um experimento chamado de mão alienígena (The Alienhand Experiment - TAHE). O objetivo de Nielsen foi estudar, por meio de uma situação experimental induzida, a consciência proprioceptiva de indivíduos e o efeito da experiência de intenção e volição sobre seu comportamento motor. $\mathrm{O}$ experimento produzia uma condição de engano visual (figura 1.) e as respostas obtidas indicariam, supostamente, o nível de consciência das próprias ações em tarefas motoras. A orientação fornecida aos participantes para a execução da tarefa era que sublinhassem uma linha preta impressa em um papel dentro de uma caixa. Na tarefa, um espelho colocado dentro da caixa refletia o movimento manual do pesquisador, que ficava do lado oposto do aparato. Ao invés de enxergarem sua própria mão, os participantes visualizavam a mão do pesquisador (mão alienígena), que propositalmente errava o traço sobre a linha, pendendo o risco para os lados. Os participantes, sem saber do truque do espelho, eram convidados a responder, após cada uma das oito tentativas, como tinha sido a experiência de executar a tarefa.

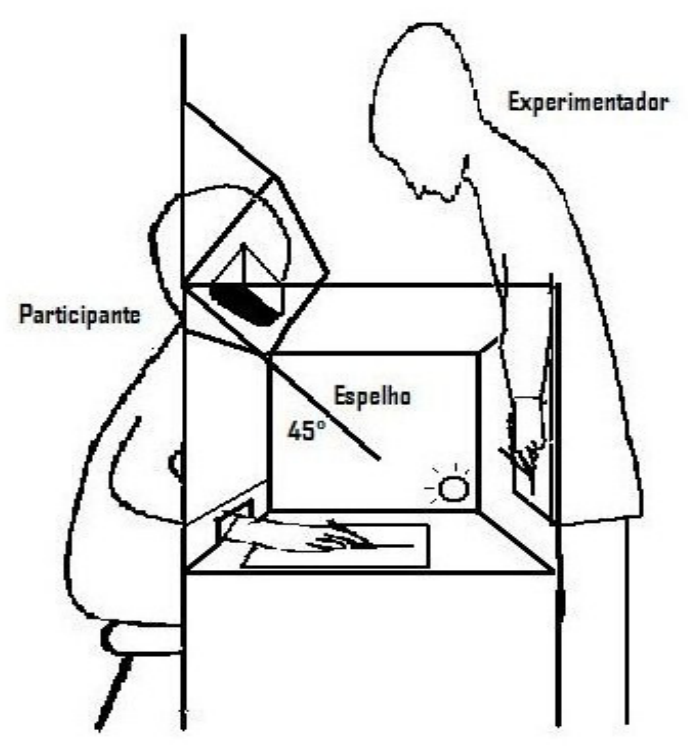

Figura 1. The Alien-hand experiment (Nielsen, 1963)

Daprati et al. (1997) utilizaram o experimento de Nielsen (1963) para examinar o autorreconhecimento, a consciência corporal e o senso de agência em indivíduos com e sem diagnóstico de esquizofrenia. Senso de agência foi definido como a habilidade de atribuir corretamente as ações à sua fonte verídica de execução. Para tanto, o aparato foi ampliado com dois espelhos, câmeras filmadoras e duas condições possíveis de visualização do movimento manual. Na primeira os participantes visualizavam o movimento da própria mão; na segunda visualizavam o movimento de uma segunda mão (a alienígena), que tentava reproduzir sua ação. Os participantes foram orientados a responder, ao longo de 36 tentativas, se o que enxergavam era a sua própria mão ou não. Os resultados obtidos indicaram que os primeiros erraram mais ao identificar a quem pertencia o movimento manual que visualizavam, evidenciando alterações nos sensos de agência e consciência proprioceptiva.

De modo similar, Van den Bos e Jeannerod (2002) examinaram o senso de autorreconhecimento e consciência da ação em 16 participantes sem diagnóstico de psicopatologia. O interessante neste estudo é que os autores, ao invés de avaliar a habilidade de atribuir corretamente as ações à sua fonte verídica de execução (agência), avaliaram as características visuais de orientação espacial dos participantes. Os resultados sugeriram forte dependência entre esquema corporal, que seria o senso proprioceptivo não consciente, e a representação 
consciente da ação, atestada pelos relatos dos participantes na tarefa.

Sorensen (2005) inovou ao replicar o experimento de Nielsen (1963) associado ao método fenomenológico para o estudo da autopercepção corpóreo-motora em mulheres com e sem o diagnóstico de bulimia nervosa. $\mathrm{O}$ autor tomou as falas dos participantes após cada tentativa para responder ao experimento e as analisou com o critério fenomenológico da Escola de Copenhague (classificação de relatos por juízes), para definir o direcionamento de agência, se para si ou para outrem. Os resultados indicaram menor senso de agência entre os participantes que apresentavam sintomas da bulimia. Nessas participantes, as respostas ao desvio visual gerado pelo reflexo do espelho evidenciaram atribuição do erro ao próprio movimento manual, ao contrário do grupo controle, que reconheceu não ser sua mão a causadora da ação na tarefa motora.

Os três estudos mencionados indicam a utilização do contexto experimental como gerador de novas experiências, espontâneas e imediatas, que, por sua vez, demandam dos participantes reações de prontidão. Esse modelo pode se mostrar profícuo em pesquisas sobre relatos de experiências, ação motora e a relação com índices de autoconsciência e reflexividade.

\section{AUTOCONSCIÊNCIA: PRÉ-REFLEXIVIDADE E AUTORREFLEXIVIDADE}

A conjunção entre relatos de percepção cinestésica e autoconsciência remete às discussões sobre intencionalidade nas obras dos fenomenólogos Edmund Husserl e Maurice Merleau-Ponty. Ambos argumentavam a favor da dimensão pré-reflexiva presente nos movimentos de ação e percepção de um sujeito no mundo (Husserl, 1907/1997; MerleauPonty, 1945/1999). A propriedade intencional da consciência, conforme proposta pela fenomenologia, seria entendida como uma predisposição direcional do fluxo de vivências que culminaria no processo reflexivo enquanto tal. Nessa medida, a autoconsciência entendida como a consciência da consciência corresponderia a um segundo momento do processo. Vale, portanto, a distinção entre autoconsciência como intenção e autoconsciência como traço de autorreconhecimento reflexivo.

De acordo com Shusterman (2008), a préreflexão para Merleau-Ponty é o elemento básico e central exercitado pelo corpo na constituição da percepção humana. Segundo Shusterman, o corpo seria o centro da capacidade expressiva, portanto, o fundamento de toda linguagem e significação. $\mathrm{O}$ autor identifica quatro níveis de consciência na concepção fenomenológica de Merleau-Ponty: 1) corporal ou motor, 2) pré-reflexivo ou espontâneo, 3) reflexivo, e 4) metarreflexivo ou consciência da consciência. O primeiro indica a intencionalidade corporal, ou intencionalidade motora. Um exemplo dessa modalidade ocorre durante o sono. Quando estamos dormindo e algum objeto, como um travesseiro, bloqueia a respiração, uma reação típica seria virar a cabeça ou afastar o objeto que atrapalha a respiração e continuar a dormir. Esta habilidade adaptativa pressupõe uma intencionalidade motora inteligente e já constituiria um nível de consciência corporal autônoma. O segundo nível, denominado de "vida irrefletida da consciência", caracterizaria uma percepção consciente sem uma consciência tematizada explícita. Um exemplo é o deslocamento de um corpo por um ambiente no qual se requer o desvio de outros corpos. Nessa situação não haveria uma consciência explicita das fronteiras precisas entre os corpos, e sim, um movimento espontâneo na busca de uma zona de conforto. O terceiro nível ocorre quando elevamos a percepção à reflexividade, seja esta percepção de objetos externos ou do próprio corpo. Este seria o nível das representações mentais. Por fim, o quarto nível corresponde ao monitoramento da consciência tematizada. Seria uma autoconsciência que influencia a percepção de refletir sobre o fluxo das vivências.

Assim, a autoconsciência não é, para a fenomenologia, algo exclusivo à inspeção atenta da própria experiência, ou um instante de autorreconhecimento de sua imagem no espelho, ou mesmo a construção de uma autonarrativa (Gallagher \& Zahavi, 2010). Os modos mais elaborados de autoconsciência, que dependem da linguagem e do raciocínio conceitual, seriam originários da modalidade pré-reflexiva de autoconsciência. De acordo com Hohwy (2007), esta asserção vincula-se a uma tendência ascendente nas neurociências em associar o senso de agência a uma concepção de self mínimo, que seria o sentimento pré-reflexivo de que um movimento é executado por mim, ou que uma dada experiência perceptiva é vivenciada por mim. Em outros termos, o self mínimo seria um sentimento instantâneo de se dar por si, sem refletir sobre isso, na vivência das coisas. A partir daí as experiências seriam codificadas. Tal concepção difere, por exemplo, do sentido autobiográfico do self narrativo, que consiste nas experiências de autorreferência como 
personagem das situações na história de vida. Tem-se, então, uma distinção clara entre a pré-reflexividade, o dado sensorial ou sentimento (cogitatum), e autorreflexão, o julgamento em si (cogito) (Synofzik, Vosgerau, \& Newen, 2008).

$\mathrm{O}$ interesse pela autoconsciência definida como estilo de reflexividade tanto constitutiva quanto momentânea inspirou à investigação de modos de autorreferência. Fenigstein, Scheier e Buss (1975) conceberam uma escala para medir a reflexividade (atenção para o Ego), sugerindo perfis de autoconsciência a partir da suposição de diferentes situações de vida. $\mathrm{O}$ instrumento foi revisado e culminou na versão de Scheier e Carver (1985), que dispõe de uma estrutura trifatorial composta por autoconsciência privada, autoconsciência pública e ansiedade social. Predominância da autoconsciência privada indicaria maior concentração nos próprios estados afetivos e nas experiências pessoais. Predominância de autoconsciência pública indicaria maior preocupação com a própria aparência e modos de se apresentar ao outro. Predominância da ansiedade social indicaria maior desconforto diante da observação de outros.

A polarização entre pré-reflexão e autorreflexão levou a dois modelos de investigação: um orientado para o processo atencional (autorreflexividade) e o outro para as características estruturais da experiência consciente (pré-reflexividade). Nesse contexto, os modelos não aparentam, em princípio, incompatibilidade operacional de pesquisa. Se os processos forem investigados conjuntamente a validade e coerência teórica dos achados poderão ser demonstradas por análises distintas, incluindo relatos da experiência (perspectiva de primeira pessoa, P1P) e medidas comparativas no desempenho diante de uma dada tarefa (perspectiva de terceira pessoa, P3P) (Gambini, Barbieri \& Scarone, 2004; Ginsburg, 2005).

\section{O PRESENTE ESTUDO}

O presente estudo comparou relatos de percepção cinestésica com perfis de autoconsciência (Scheier \& Carver, 1985) no desempenho de tarefa motora induzida pelo aparato experimental da mão alienígena (Nielsen, 1963). Pergunta-se, então: 1) Os relatos dos participantes durante a tarefa experimental qualificam os perfis de autoconsciência privada, pública e ansiedade social? 2) Em caso positivo, haveria predominância de algum perfil de autoconsciência privada, pública e ansiedade social no reconhecimento da mão alienígena e subsequente argumentação (qualificação) sobre sua interferência no desempenho da tarefa? Por qualificação indica-se o quale, a manifestação vivencial à percepção cinestésica, isto é, como o fluxo do autorrelato movimenta-se da intenção corporal (reconhecimento da ação motora) à metarreflexão (julgamento do desempenho ou senso de agência). Em contraste, a especificação de índices serve de verificação procedural ao conceito de autoconsciência assumido por Fenigstein, Scheier e Buss (1975), isto é, a verificação do mesmo fenômeno por outro método (lógica adutiva). A expectativa é que haja diferença entre participantes no reconhecimento da mão alienígena, e que a referência dos participantes às vicissitudes do desempenho revele o movimento intencional do ato consciente (noese) entre julgamentos provisórios e conclusivos (noemas) durante a experiência.

\section{MÉTODO}

O presente estudo consiste em um experimento fenomenológico (Lanigan, 1997) no qual a conjunção moderna da extensão humana (ação) e da intensão ${ }^{2}$ humana (compreensão) são articuladas como problema comum à corporeidade e ao discurso, reunindo perspectivas de terceira (P3P) e de primeira pessoa (PIP). Tomados de P1P serão obtidos em relatos dos participantes após o desempenho de uma tarefa $\left(\right.$ capta $\left.^{3}\right)$; dados de P3P serão obtidos por observações digitais e por medidas de perfis de autoconsciência $\left(\right.$ data $\left.^{4}\right)$.

\section{Participantes}

Participaram do experimento 19 estudantes universitários voluntários, sendo 9 do sexo masculino e 10 do sexo feminino, alunos de graduação de uma instituição pública de ensino superior no sul do Brasil. A média de idade dos participantes era de 23,16 anos $(\mathrm{DP}=2,754)$. Dos 19 voluntários, apenas dois eram sinistros. Foram cumpridas as exigências éticas para a realização de pesquisa com seres humanos.

\section{INSTRUMENTOS}

Foram utilizados três instrumentos: 1) Escala de autoconsciência revisada - EAC-R; 2) Aparato

\footnotetext{
2 Do latim intensio(-onis) - lógica, i.e conotação, para além do sentido literal, compreensão.

3 Capta, do latim, quod erat inveniendum, i.e, o que é tomado, compreensão fenomenológica.

4 Data, do latim, quod erat demonstrandum, i.e, o que é demonstrado por observações e medidas.
} 
experimental da mão alienígena (TAHE); e 3) um Protocolo para entrevista pós-experimento.

A Escala de autoconsciência revisada - EAC-R (Scheier \& Carver, 1985) foi elaborada a partir de revisão empreendida na escala original EAC (Fenigstein, Sheier \& Buss, 1975). É composta por 22 itens com escala tipo Likert de cinco pontos, em que "0" representa "nada característico" e "4" "extremamente característico". O instrumento é composto por uma estrutura trifatorial, a saber: autoconsciência privada (nove itens - ex: "Eu estou sempre tentando me entender"), autoconsciência pública (sete itens - ex: "Eu me preocupo com a maneira como me apresento"), e ansiedade social (seis itens - ex: "É difícil para mim trabalhar quando há alguém me olhando"). Avalia traços de autoconsciência emitidos segundo o juízo autoperceptivo (autorreflexão) dos respondentes quanto à sua tendência de conduta no cotidiano. A versão adotada na pesquisa foi a traduzida e validada para a população brasileira por Teixeira e Gomes (1996). Esta versão, além de obter uma confiabilidade aceitável (0,73 para coeficiente de alfa e 0,89 para teste-reteste), confirmou a estrutura trifatorial da versão original.

$\mathrm{O}$ aparato experimental da mão alienígena (TAHE) consiste em uma caixa de madeira (45 X 45 $\mathrm{X} 45 \mathrm{~cm}$ ) com uma pequena abertura na base (20 X 15 $\mathrm{cm})$ para a entrada da mão do participante e um tubo na parte superior $(15 \times 12 \mathrm{~cm})$ que possibilita a visualização ao interior da caixa. Na parte posterior do aparato há uma abertura maior (45 X $35 \mathrm{~cm}$ ), que permite ao pesquisador acesso amplo ao interior da caixa. Esta abertura não é visualizável para o participante. Fixado dentro da caixa, em uma angulação de $45^{\circ}$, desde o visor até pouco mais da metade da caixa, há um espelho $(43$ X $30 \mathrm{~cm})$. Ainda dentro do console há uma lâmpada fixada na base, a qual é acionada pelo pesquisador por um interruptor externo. A tarefa induzida foi composta por quatro tentativas, nas quais os participantes foram solicitados a riscar uma linha preta vertical pré-impressa em uma folha de papel branco e relatar sua experiência da tentativa.

O protocolo de entrevista pós-experimento é um roteiro de poucas perguntas sobre a experiência de participação na tarefa induzida ("Como você se sentiu ao longo do experimento?"; "A experiência lhe trouxe alguma reflexão / pensamento específico sobre o exercício?"; "Você sentiu ou pensou diferenças entre uma tentativa e outra?"). As respostas foram gravadas em audioteipe e posteriormente transcritas para análise.

\section{Procedimentos}

Os participantes foram abordados aleatoriamente no campus universitário e convidados a participar de um experimento sobre "autopercepção de ações motoras e consciência corporal". Antes da realização do experimento os participantes receberam uma explicação dos objetivos da pesquisa e em seguida assinaram um termo de consentimento livre e esclarecido. Em prosseguimento, solicitou-se aos participantes que respondessem a Escala de Autoconsciência Revisada - EAC-R (Scheier \& Carver, 1985). Após o preenchimento do instrumento, os participantes foram instruídos a vestir uma luva de borracha de cor azul. Sobre a mesa, em frente ao participante, havia uma folha de papel branco (formato A4) com uma linha preta impressa na posição vertical. O experimentador sugeria ao participante que sublinhasse com uma caneta esferográfica a linha reta com a mão da luva, como um teste para a tarefa que ocorreria em seguida. Já sentados em frente à caixa do TAHE, os participantes foram instruídos a executar a mesma tarefa realizada pouco antes na mesa, mas agora com a folha de papel depositada no interior da caixa. O sinal para iniciar a tarefa é o acionamento da luz dentro da caixa, ficando ela acesa por dois segundos a cada tentativa. Os participantes são então conduzidos a direcionar seu olhar, por meio de um visor, para a tarefa que estão desenvolvendo. Ao invés de visualizar sua própria mão executando a tarefa, o participante enxerga uma folha de papel idêntica à sua, refletida pelo espelho, na face oposta da caixa. Vestindo uma luva idêntica, o experimentador, simultaneamente, risca a linha que supostamente estaria sendo traçada pelo participante.

$\mathrm{O}$ experimentador foi orientado a traçar a linha da forma mais semelhante possível ao modo como o participante desenvolve a tarefa. Como os sujeitos desconhecem o "truque do espelho", inicialmente supõem ver suas próprias mãos. Justifica-se que o experimentador se coloca do outro lado da caixa, escondido sob cortinas, para trocar as folhas a cada tentativa sem influenciar os sujeitos por suas expressões faciais, dentre outras eventuais interferências. Após as tentativas o pesquisador inicia a entrevista roteirizada. A expectativa é que no final do experimento os participantes reconheçam a mão alienígena. Ao final, a utilização da mão alienígena é explicada aos participantes.

\section{Análise dos dados}

Primeiro procedeu-se à análise fenomenológica dos tomados experienciais (capta), seguida pela comparação das distribuições da EAC-R entre os 
grupos definidos na análise fenomenológica (data). As articulações entre corporeidade e discurso serão contempladas tanto na análise fenomenológica quanto na comparação de grupos por análise estatística. $\mathrm{Na}$ análise fenomenológica (Gomes, 2007), os relatos dos participantes (P1P) foram comparados e contrastados entre si, com o objetivo de levantar qualificantes que tipificassem a tarefa. A descrição dos relatos foi analisada com o seguinte critério: 1) suspensão de crenças na realidade valorativa sobre as respostas apresentadas ao experimento (epoché); 2) exame das essencialidades comunicacionais manifestas em sentimentos, entendimentos, e valores (redução fenomenológica); 3) compreensão do movimento intencional do reconhecimento da mão alienígena conforme vivenciada na intersubjetividade da pesquisa (interpretação fenomenológica). A análise estatística constou da descrição das médias por fatores e geral da escala, para identificação e definição dos perfis de autoconsciência (privado, público, e ansiedade social), além de uma comparação entre os gêneros masculino e feminino. Por fim, compararam-se os perfis definidos pelas escalas com o reconhecimento ou não da mão alienígena (tipificação fenomenológica).

\section{RESULTADOS}

\section{Análise fenomenológica (capta)}

A descrição fenomenológica da experiência dos participantes focalizou dois momentos do experimento: 1) as respostas às perguntas após cada tentativa, e 2) a breve entrevista pós-experimento. Assim, durante a execução do traçado o participante mantinha-se concentrado, não falava, mas reagia facialmente à distorção percebida entre visualização e a ação (sorrisos, suspiros). A resposta à pergunta pós- tentativa era breve (cerca de duas ou três frases). Os conteúdos foram variados, versando, de modo geral, sobre aspectos vivenciais, tais como estranhamento na realização da tarefa, dificuldade de execução e sensações de confusão ou incompreensão do que estava ocorrendo. Quando o participante reconhecia o truque experimental, especulava sobre o mecanismo envolvido na ação, perguntando se havia algum espelho, ou mesmo um vídeo. Quando o participante não reconhecia o truque, alegava dificuldades na realização tarefa, como, por exemplo, ter que fazer muitas coisas ao mesmo tempo, ou que fazer o traçado na caixa era diferente de fazê-lo sobre a mesa. $O$ reconhecimento do truque associava-se à percepção mais acurada da sincronia entre o traçado do participante e a visualização, com a alegação de que a resposta visual estava sempre atrasada.

As respostas à entrevista pós-experimento foram mais longas, já mediadas por argumentação objetiva e com explicações ou interpretações sobre as causas e características do experimento. Referências à sensação de estranhamento ou surpresa apareciam novamente, mas desta vez como uma evidência de antecipação para as ações subsequentes. $\mathrm{O}$ participante informava que a realização do primeiro traçado criava uma compreensão que direcionava as compreensões seguintes a serem ou não confirmadas. Para uma parte dos respondentes, o desafio serviu para buscar melhor adaptação à tarefa a partir da dificuldade ou do estranhamento encontrados na primeira tentativa. Para a outra parte, o desafio foi identificar ou solucionar a origem desse estranhamento.

A redução fenomenológica contrastou partes dos relatos entre si e entre os participantes, conforme ilustra a tabela 1. com dois exemplos emblemáticos do experimento: reconhecimento explícito (I) e reconhecimento ambivalente da mão alienígena (II).

Tabela 1. Tentativas e classes de argumento para disparidade viso-motora

\begin{tabular}{|c|c|c|c|c|}
\hline $\begin{array}{l}\text { Grup } \\
\text { o }\end{array}$ & $1^{a}$ & $2^{a}$ & $3^{a}$ & $4^{a}$ \\
\hline (I) & $\begin{array}{l}\text { Foi estranho. Minha mão } \\
\text { não corresponde ao que } \\
\text { estava no visor. }\end{array}$ & $\begin{array}{l}\text { Mesma coisa. Não é minha } \\
\text { mão. } \\
\text { O movimento da minha mão } \\
\text { é diferente do que eu estou } \\
\text { fazendo. }\end{array}$ & $\begin{array}{l}\text { Mesma coisa. É uma } \\
\text { imagem estranha, não } \\
\text { consigo entender. Porque } \\
\text { não parece um vídeo, parece } \\
\text { que é uma imagem bem } \\
\text { definida e tal, mas é } \\
\text { diferente. Não é minha } \\
\text { mão. }\end{array}$ & $\begin{array}{l}\text { Mesma coisa, não } \\
\text { corresponde aos } \\
\text { movimentos que eu faço. }\end{array}$ \\
\hline (II) & $\begin{array}{l}\text { Foi bem estranho. Tinha um } \\
\text { desvio, não consegui ter } \\
\text { coordenação motora. }\end{array}$ & $\begin{array}{l}\text { Consegui recalcular melhor, } \\
\text { mas mesmo assim perco o } \\
\text { sentido do movimento. }\end{array}$ & $\begin{array}{l}\text { Continuo sentindo } \\
\text { dificuldade de coordenar. } \\
\text { Não sei se é a distância ou a } \\
\text { amplitude do movimento. }\end{array}$ & $\begin{array}{l}\text { Mesma dificuldade. Não } \\
\text { entendo porque não } \\
\text { consigo botar o braço na } \\
\text { linha. }\end{array}$ \\
\hline
\end{tabular}


Da sequência de cada série de quatro respostas, emerge um contraste aparentemente óbvio: a manutenção da compreensão inicial ou revisão e modificação da compreensão inicial. Os conteúdos das respostas sugerem duas categorias temáticas: referências à ação (a mão não correspondente ao visor, a imagem é estranha, os movimentos não correspondem, não é minha mão, não há imagem, é só um jogo), e referências a objetos (mão, espelho, luz, luva, etc.); no entanto a análise temática restrita não evidencia as especificidades do movimento da consciência para a tarefa (intenção). Nesse sentido, já se esperava a surpresa inicial entre os participantes quanto à não correspondência entre intenção do ato motor e resultado da ação. A novidade veio com as explicações dos participantes sobre a disparidade entre ação e resultado, ou seja, a redução encaminhou-se para o argumento das explicações, tanto nos relatos breves quanto nas respostas à entrevista.

Os argumentos variaram em dois sentidos. Uma classe de argumentos atribuiu a disparidade visomotora, desde a primeira tentativa, à existência de algum mecanismo de distorção na caixa (I); a outra classe atribuiu a disparidade a um problema de adaptação à condição experimental (II). As duas classes de argumentos foram então interpretadas como perfis atitudinais em relação à tarefa. No primeiro grupo encontram-se 11 sujeitos que afirmaram a distinção entre ação e visualização da ação por interferência externa. Esses participantes foram identificados como pertencentes ao Grupo I reconhecimento explícito. $\mathrm{O}$ segundo grupo refere-se à autoatribuição da disparidade entre ação e resultado, mesmo reconhecendo as dificuldades ou estranhamento na execução da tarefa. Esses oito participantes foram identificados como pertencentes ao grupo II - reconhecimento ambivalente.

A interpretação fenomenológica vai se concentrar na conjunção entre extensão humana (ação) e intensão humana (compreensão) como articulação expressiva da corporeidade na execução motora da tarefa, na percepção cinestésica e no discurso. $\mathrm{O}$ discurso para cada tentativa, como indica a tabela 1 , mostrou o fluxo reflexivo ou a consciência em progresso enquanto compreensão provisória. $\mathrm{Na}$ primeira tentativa os discursos caracterizaram-se por duas tipificações nativas, compreendidas como sentimento de estranhamento (foi estranho/foi bem estranho) e percepção do desacordo entre ação e visualização (tinha um desvio/minha mão não correspondeu). Poderíamos interpretar esse primeiro passo reflexivo como Cogitatum, conforme Husserl (1907/1997), préreflexão, conforme Merleau-Ponty (1945/1999), ou significante, conforme Lanigan (1997). A experiência está sendo delimitada para a consciência com predomínio do apoderamento afetivo (o que eu sinto). $\mathrm{Na}$ segunda tentativa, a consciência é especificada e a experiência começa a ser diferenciada. Os discursos transformam o sentimento em julgamento (não é minha mão/perco o sentido do movimento). Poderíamos interpretar esse segundo passo como Cogito conforme Husserl, reflexão, como MerleauPonty, ou significado, conforme Lanigan. $\mathrm{O}$ ausente (o que é) se torna presente (é isso) e o apoderamento é cognitivo. As terceira e quarta tentativas se mostraram redundantes, mas confirmatórias enquanto movimento reflexivo. Os discursos afirmam-se como valorativos e conclusivos (não é minha mão/não consigo botar o braço na linha). Poderíamos interpretar esses últimos passos como Ego, conforme Husserl, como sentido, conforme Merleau-Ponty ou como signo, conforme Lanigan. O presente transforma-se em capacitação (não é minha mão) ou em ambivalência (não consigo botar o braço na linha), e o apoderamento é conativo (posso/não posso). A análise esclarece a virada fenomenológica da compreensão analógica para a especificação digital, dividindo os participantes nos dois grupos já indicados: reconhecimento explícito e reconhecimento ambivalente.

\section{Análise estatística (data)}

Realizou-se a comparação da distribuição dos valores da EAC-R entre os grupos definidos pela análise fenomenológica. Adicionalmente foram realizados cálculos de magnitude de efeito para médias $(d)$, considerando-se a limitação de cálculos inferenciais baseados em hipótese nula $(p)$, especialmente para estudos clínicos e/ou experimentais em psicologia (Conboy, 2003).

Na comparação entre o grupo I (reconhecimento explícito da mão alienígena) e o grupo II (reconhecimento ambivalente) utilizou-se o teste não paramétrico U de Mann-Whitney. Encontrou-se diferença significativa para o resultado geral da escala $(\mathrm{p}=0,004)$ e para o fator autoconsciência privada $(\mathrm{p}=0,042)$. Não ocorreram diferenças significativas entre gênero, com ressalva para o item 14 da escala ("Eu constantemente penso sobre a razão das minhas ações") $(p<0,05)$, com distribuição mais elevada para as mulheres.

Por outro lado, o cálculo de magnitude de efeito, que nesse estudo utilizou a fórmula de Cohen (1992), indica diferenças elevadas entre as médias do grupo I e grupo II para os três subfatores da escala, bem como para a média geral do instrumento. Conforme Cohen, valores $d$ acima de 0.80 indicam magnitude de efeito 
elevada. Os resultados evidenciaram que participantes com maior dificuldade na indicação ou mesmo no reconhecimento da mão alienígena (grupo II reconhecimento ambivalente) foram os que obtiveram maiores níveis de autoconsciência privada $(d=1.57)$, autoconsciência pública $(d=1.17)$, ansiedade social $(d=1.38)$, e resultado geral da escala $(d=2.12)$.

\section{CONCLUSÕES}

Neste experimento com a mão alienígena, o relato dos participantes não só trouxe aspectos importantes do fluxo consciente, mas também justificou o correlato qualitativo (ou...ou) de ou reconhecimento explícito ou reconhecimento ambivalente com perfis de autoconsciência. Participantes com reconhecimento ambivalente do truque experimental apresentaram escores mais altos em todos os fatores da escala de autoconsciência, mais acentuadamente no fator autoconsciência privada. Assim, a primeira conclusão é que a predisposição à atividade reflexiva enquanto atenção para si mesmo comprometeu a Gestalt radical visomotora da tarefa, seja por não descriminá-la seja por não enfrentá-la.

O fluxo discursivo (P1P) entre pré-reflexão (descritivo), reflexão (argumentativo) e metarreflexão (conativo) pode ser tomado como evidência da objetividade da consciência, que é a relação entre o ato intencional (noese) e o objeto conceitual (noema). No experimento, o fenômeno apresentou-se na transformação do objeto real da mesma experiência vivida de diferentes modos (o contato com o aparato experimental - o vivido) para o objeto conceitual (noema - o percebido). Então, a segunda conclusão é que o experimento da mão alienígena, ao criar um impasse entre corporeidade e discurso, desvela o movimento intencional da consciência em sua gênese.

A associação entre predominância de atenção voltada para si mesmo, conforme a definição de autoconsciência dos autores da EAC-R (P3P), e o reconhecimento ou não da mão alienígena, requerem, ainda, uma interpretação fenomenológica que certamente não será hermenêutica, e sim, constitutiva. Os perfis de autoconsciência indicados pela EAC-R referem-se à noese, a estrutura do ato intencional que é a modalidade habitual de proceder da atenção no dirigir-se ao objeto conceitual, com maior ou menor mediação do Ego. Tal condição remete ao conceito de epoché, que é o reconhecimento crítico à impregnação do ato intencional pelo Ego e também da necessidade de reduzir tal interferência, pondo-a à parte do foco atencional; no entanto a condição cinestésica e pré-reflexiva do experimento criou uma situação de ambiguidade proprioceptiva, pois comprometeu a informação sensória e desarticulou a unidade corporal, constituindo um desafio autorreflexivo. Neste estudo, o limitado número de repetições da tarefa (quatro vezes) estabeleceu uma contingência temporal e criou a expectativa de uma resposta: ou "a minha mão não consegue" ou "não é minha mão." Mudanças em contingências temporais (número de tentativas para a realização da tarefa) e estruturais (comprometimento da unidade visomotora) podem gerar inseguranças, revisões de julgamento e autocrítica. Então, a terceira conclusão é que neste experimento o perfil de autoconsciência comprometeu o senso de agência, impedindo a realização visomotora, e, por conseguinte, o fluxo discursivo entre o sensorial pré-reflexivo e o consciente reflexivo. Não obstante, tal conclusão é problemática, pois não esclarece o que efetivamente ocorre com a diferenciação dos perfis. Por exemplo, a dificuldade apresentada pelo grupo de participantes mais voltados para si seria decorrente de maior envolvimento do Ego e desconfiança de si mesmo? Por outro lado, o reconhecimento do truque experimental poderia indicar maior prontidão à tarefa, maior sensibilidade cinestésica ou menor envolvimento do Ego?

$\mathrm{O}$ confronto das conclusões do presente experimento com as de outros realizados anteriormente associa a dificuldade apresentada ao senso de agência pelos perfis com maiores escores em autoconsciência: 1) aos participantes com diagnóstico de esquizofrenia do estudo de Daprati et al. (1997), e 2) aos participantes com diagnóstico de bulimia nervosa no estudo de Sorensen (2005). Tais conclusões nos levam a pensar numa possível associação entre maior atenção voltada a si mesmo, como indica a EAC-R, e baixa representação da ação, conforme indica o estudo de Van der Bos e Jeannerod (2002). Se forem confirmados por futuros estudos, esses resultados sugerem também maior exploração ao poder preditivo desta surpreendente e simples EAC-R, pelas suas possíveis ligações com o self mínimo, conforme Hohwy (2007), objeto de interesse das neurociências (Petit, 2010).

O experimento da mão alienígena mostrou-se promissor para o estudo do senso de agência e da unidade corporal como base para a autorreflexão. Por sua vez, a combinação de perspectivas de primeira e de terceira pessoa apresentou bom potencial elucidativo aos dados experimentais. Deste modo, o modelo da mão alienígena poderá ser explorado tanto para a replicação desses achados quanto para a introdução de variações como modificações e refinamento no aparto experimental e variações 
populacionais. É um modelo profícuo para o estudo tanto das ciências cognitivas quanto da própria teoria fenomenológica.

\section{REFERÊNCIAS}

Cohen, J. (1992). Quantitative methods in psychology: A power prime. Psychological Bulletin, 112(1), 155-159.

Conboy, J. E. (2003). Algumas medidas típicas univariadas da magnitude de efeito. Análise Psicológica, 21(2), 145-158.

Daprati, E., Franck, N., Giorgieff, N., Proust, J., Pacherie, E., Dalery, J., \& Jeannerod, M. (1997). Looking for the agent: an investigation into cousciuousness of action and selfconusciousness in schizophrenic patients. Cognition, 65, 71-86.

Farrer, C., \& Frith, C. D. (2002). Experiencing oneself vs another person as being the cause of an action: the neural correlates of the experience of agency. Neuroimage, 15(3), 596-603.

Fenigstein, A., Scheier, M.F., \& Buss, A.H. (1975). Public and private self-consciousness: assessment and theory. Journal of Consulting and Clinical Psychology, 43(4), 522-527.

Gallagher, S., \& Sorensen, J.P. (2006). Experimenting with phenomenology. Consciousness and Cognition, 15(1), 119-134.

Gallagher, S., \& Zahavi, D. (2010). Phenomenological approaches to self-consciousness. Stanford Encyclopedia of Philosophy (Winter 2010 Edition), Edward N. Zalta(ed.), Recuperado em 04 de Agosto, de 2011, de http://plato.stanford.edu/entries/selfconsciousness-phenomenological/.

Gambini, O., Barbieri, V., \& Scarone, S. (2004). Theory of Mind in schizophrenia: First person vs third person perspective. Consciousness and Cognition: An International Journal. 13(1), $39-46$

Ginsburg, C. (2005). First person experiments. Journal of Consciousness Studies, 12 (2), 22-42.

Gomes, W.B. (2007). A distinção de procedimentos técnicos e lógicos na análise fenomenológica do exercício didático: o que é uma boa aula de psicologia? Revista da Abordagem Gestáltica, 13(2), 228240.

Grush, R. (2006). How to, and how not to, bridge computational cognitive neuroscience and Husselian phenomenology of time consciousness. Synthese, 153, 417-450.

Hohwy, J. (2007). The sense of self in the phenomenology of agency and perception. Psyche, 13(1), 1-20.
Husserl, E. (1997). Thing and Space: Lectures of 1907. Netherlands: Kluwer Academic Publisher. (Original em língua alemã publicado em 1973).

Lanigan, R. (1997). Capta versus Data: Método e evidência em comunicologia (C. H. Kristensen, Trans). Psicologia: Reflexão e Crítica, 10(1), 17-45.

Merleau-Ponty, M. (1999). Fenomenologia da Percepção. São Paulo: Martins Fontes. (Original publicado em 1945).

Nielsen, T. I. (1963). Volition: a new experimental approach. Scandinavian Journal of Psychology, 4(4), 225-230.

Petit, J-L. (2010). Intention in phenomenology and neuroscience: intentionalizing kinesthesia as an operator of constitution. Em F. Grammont, D. Legrand, \& P. Livet (Eds.), Naturalizing Intention in Action (pp. 269-292). Cambridge, MA: MIT Press.

Scheier, M.F., \& Carver, C.S. (1985). The self-consciousness scale: a revised version for use with general populations. Journal of Applied Social Psychology, 15, 687-699.

Shusterman, R. (2008). Body consciousness: a philosophy of mindfulness and somaesthetics. New York: Cambridge University Press.

Silvia, P. J., Jones, H. C., Kelly, C. S., \& Zibaie, A. (2010). Trait selffocused attention, task difficulty, and effort-related cardiovascular reactivity. International Journal of Psychophysiology, 79, 335340 .

Sorensen, J. B. (2005). The alien-hand experiment. Phenomenology and Cognitive Science, 4, 73-90.

Synofzik, M., Vosgerau, G., \& Newen, A. (2008). Beyond the comparator model: a multifactorial two-step account of agency. Consciousness and Cognition, 17(1), 219-239.

Teixeira, M., \& Gomes, W.B. (1996). Escala de autoconsciência revisada (EAC-R): características psicométricas numa amostra de adolescentes brasileiros. Arquivos Brasileiros de Psicologia, 48(2), 78-92.

Van den Bos, E., \& Jeannerod, M. (2002). Sense of body and sense of action both contribute to self-recognition. Cognition, 85, 177-187.

Recebido em 27/11/2009 Aceito em 16/08/2011

Endereço para correspondência:

Thiago Gomes de Castro. Rua 8 de Julho, 95, apt. 403, Bairro Jardim Botânico, CEP 90690-

240, Porto Alegre-RS, Brasil.E-mail: tgomesdecastro@yahoo.com.ar. 